\title{
Disruptive Innovation in Active Activity-Based Learning Methodologies through Digital Transformation
}

\author{
Mario Chauca, Ynes Phun, Olga Curro, Carmen Chauca, Ramiro Yallico, and Virgilio Quispe
}

\begin{abstract}
This article develops the proposal of a disruptive innovation in learning methodologies based on active activity through digital transformation. The vertiginous changes that have taken place a few decades ago with respect to the advancement of knowledge and technology, encompass educational processes. Traditional teacher-centered teaching has led to student-centered learning, seeking to develop the skills necessary for performance beyond the professional field. There are tools or supports based on current knowledge that can set trends in the educational process. The portable tool for universities to quickly and up-to-date access to information are digital devices, the use of which is becoming popular in education.
\end{abstract}

Index Terms-Innovation, methodologies, learning, transformation, digital.

\section{INTRODUCTION}

Disruptive innovation attempts to establish a connection between theory and practice, and to establish a perfect connection between the basis of epistemology and educational practice [1]. Therefore, the basic objective of innovation is to acquire the skills and abilities necessary to solve problems and develop projects in a creative way, and to rely on new technologies to improve the positive attitudes of students.

The use of new technologies and digital tools requires changes in educational practices and becomes an important part of any innovation process [2]. As technology advances, disruptive innovations have emerged to adapt new tools to the needs of teachers. In this case, the teachers must be able to build work plans through the constructive use of new technologies to incorporate them into the classroom.

From this perspective, the innovation process [3] modifies the traditional education paradigm because it affects the teaching process adopted by teachers on the one hand, and the learning strategies adopted by students on the other. Therefore, the experience and participation of the teaching staff are the key elements of innovation, since the development of educational proposals that promote the advancement of new technologies will depend on them [4].

All of this requires planning new and more flexible

Manuscript received August 30, 2020; revised January 15, 2021.

Mario Chauca is with the Ricardo Palma University, Surco, and Lima Perú (e-mail: encinas_2010@hotmail.com, mario.chauca@urp.edu.pe).

Ynes Phun, Olga Curro, Carmen Chauca, and Ramiro Yallico are with University San Luis Gonzaga, Ica, Perú (e-mail: liebre1063@gmail.com, olgacurro@yahoo.com, ereyece@hotmail.com).

Virgilio Quispe is with the I.E.S.T.P. Fernando León de Vivero, Las Nieves 100, Ica 11003, Perú (e-mail: vqn64@ hotmail.com). teaching strategies to promote innovative experiences in the training process supported by ICT (Information and Communication Technologies). Digital tools provide an easy-to-use interactive work environment that can promote the development of innovative projects [5].

Therefore, new technologies become a means not only to provide new forms of communication, but also to organize and manage the training process to promote active activities and student learning. This means generating a well thought out process of systematic change to effectively achieve training objectives [6]. From this perspective, the process of innovation through technological tools requires an important redefinition and redefinition of the educational function, which implies giving a greater role to students and making them the main drivers of the training process.

Therefore, starting from the subject of educational informatics of the pedagogical profession, a great effort has been made to enhance the activity of teachers through the development of projects that involve the use of digital transformation in teaching, as described in the next section.

Digital transformation means that, like other industries, the development of universities and higher education institutions is focused on the application of technology. Dewar [7] defines University 4.0 as a university for others, mainly at the service of students. These students are externally focused, engaged and in contact with the surrounding production environment, which is in line with Barnett [Barnett] Ecological University the concept of ecological university [8], which refers to the interconnection between the university and diverse ecosystems (knowledge, social institutions, and people, economy, learning, culture and natural environment).

Precisely, to adapt to the logical sequence up to version 4.0, Barnett [8] described the evolution of the university in different stages: a university, which was a metaphysical university developed in the Middle Ages (the main European universities date back to century XI), has a strong existence and advantages of spiritual and religious beliefs, and gradually became a popular art education. Version 2.0 appeared in the field of postindustrial society, focusing more on the deployment of research within the university as an engine of technological advancement towards economic development. It corresponds to the university founded in the 15 th century, and its teaching is accepting more and more different ways of thinking.

A few centuries later, version 3.0, which could be described as the entrepreneurial university, defined by Barnett [8], as a university by itself, serving many diverse functions and communities, but above all concerned with optimizing its own interest or strategy in an increasingly competitive world. This 3.0 University is also defined by 
Pulido [9] as an advanced and social university, which developed in Europe in the nineteenth century, combining the teaching and research functions, with self-government and institutional autonomy.

Dewar [7] argues that University 4.0 will provide on-demand learning in multiple formats, with a continuous transfer between different modalities, with a more intense collaboration between universities and the productive network in a digitized environment. In this context, [9] interprets the University 4.0 as a university subjected to such a disruptive change as to demand a radically new university (4.0) in organization, technology and educational-research strategy that responds to the needs of a deeply evolved society.

Indeed, digital technologies are fostering digital transformation, a new form of organization and growing and unpredictable changes, generating a wide range of new challenges. It is, therefore, the University 4.0 that corresponds to a modern university, as a metamorphosis of the previous versions in a technological environment that advances in the digital age and that has to respond to the demands and commitments of a globalized society.

We present in the following section a reference to the situation of digital transformation with special emphasis on Spanish universities to approach this concept of University 4.0. Next, we delve into the conceptualization of innovation in the university environment to end with some conclusions referring to the challenges and pending challenges

\section{Methodology}

The concept of digitization is perfectly extended in our society, already from the presence of the Internet in the daily work of citizens. The use of information and communication technologies (ICT), as a transforming element that affects the entire society, is a reality and with special intensity in some productive sectors (where education plays a prominent role).

The University does not live apart from this digital transformation, but it is necessary to point out and perhaps insist, due to the resistance to change that the adoption of a digital strategy is much more than the incorporation and habitual use of the Internet and digital media. At present, the new ICTs are a fundamental tool in the daily performance of university activity. There is no doubt that the use of ICT has meant a change in the performance of academic life, in the processes and development of tasks, training, learning and teaching, the way of researching and transferring its results to the society. Together, these changes have been called digital innovation, and although it is an important step, it is still insufficient.

A first stage of the situation analysis refers to the starting point of the Spanish university. In this regard, the Conference of Rectors of Spanish Universities (CRUE) has produced since 2006 the annual report UNIVERSITIC, Analysis of ICT in Spanish universities, where it collects the state of the Spanish university system in relation to the ICT implemented and assessed by a group of quantitative indicators.

In some way, the initial ICT reports from the universities were precursors to the development of the 2010 Digital University White Paper [10], which proposed a reference guide for universities to successfully face the challenge of adapting to the society of the knowledge based on digital development. A reference model to provide adequate digital support (infrastructures and their management) to the fundamental missions of the University (teaching, research and transfer, management). A model in which you have to believe in order for it to become a reality, where a digital leadership strategy is essential.

In a detailed analysis, we find, on the one hand, information technology (IT) description indicators related to: teaching-learning, research, management processes, information management, and training and culture. On the other hand, management indicators

IT related to: resources, projects, services, direction, quality, regulations and collaboration. The latest UNIVERSITIC report available, referring to 2017 and published in 2018, reveals an advanced state and close to its saturation level regarding the basic implementation of IT and technological equipment in Spanish universities as support and support for both face-to-face and virtual teaching (software licenses, computer rooms), with an attention and budgetary allocation already consolidated.

Learning by projects (ApP) is a didactic strategy

Based in he designs of activities interdisciplinary. In them, students must offer a practical application, in the real world beyond the limits of the classroom [11]. They are projects based on the investigation of real situations or problems, establishing a connection between the academic world and the work world.

With project-based learning, student motivation is increased since it helps to contextualize the training process and offers new opportunities for collaboration [12]. At the same time, skills and competencies are developed and consolidated, such as social and communication skills, problem solving, decision-making, etc. Therefore, given the contributions and benefits of this didactic strategy to enhance and promote learning, it has been used in the Educational Informatics subject as a means for teachers to put the acquired knowledge into practice.

Similarly, project-based learning based on the integration and use of digital tools supposes an important change in the teaching processes that until now had been applied in the subject, establishing a transformation in the training model, proposing more educational practices. Close to the world of work, where new tools and technological resources occupy a predominant place.

A disruptive innovation in education requires the development of an open and flexible teaching model based on the omnipresence of new technologies and a high degree of collaboration. In this sense, with the collaborative experience carried out-, focused on learning by projects-, it is estimated that an innovative process is promoted by proposing motivating and attractive training practices, capable of favoring the curricular integration of ICT.

\section{A. Context and Objectives of the Experience}

During the academic year in the Educational Informatics subject of the Pedagogy degree, a training activity based on project-based learning (ApP) was carried out. In it, the students, collaboratively, had to design an educational 
project of digital curricular integration based on previously established assumptions.

In this way, with the APP approach, two fundamental objectives were pursued: on the one hand, to give students the opportunity to design a practical application of the use of new technologies, as close as possible to the educational reality, in which put into play all the knowledge acquired throughout the course. And on the other, to encourage teachers to make use of higher order cognitive skills to promote meaningful learning.

\section{B. Work Methodology}

To carry out the design of the ICT integration project, the students were presented with a series of guidelines that they had to follow for its proper development. Thus, at first, they were presented with the foundations from which they should plan their educational interventions. For this, the strategy of the case study was used. A case study, as stated [13] is "the examination of an example in action". In this sense, the following case study was presented to the students:

\section{1) Context}

In the East of Asturias (Spain) there is a rural school with 6 children, corresponding to the following courses: 1 child from the last year of Early Childhood Education; 1 girl from 1st of Primary Education; 2 children from 3rd grade of Primary Education; 1 girl from 4th grade of Primary Education; and 1 child from 5th grade of Primary Education.

All children share the same classroom and academic schedule. They are all good students and have computers at home (but no internet connection). They have basic knowledge in using computers. Her parents are very involved in the activities that take place at school.

You must position yourself as a teacher in this rural school that only has one classroom in which all the students are grouped.

\section{2) Technological provision of the classroom}

The classroom is equipped with 5 desktop computers (two of them somewhat old). On the teacher's table there is a computer with a digital whiteboard.

All computers have an Internet connection, but it is a slow connection as the school is far from urban areas.

\section{3) Objective}

The Ministry of Education launches a call for competition to all rural schools to present a Good Practice with the use of ICT in their classrooms.

You as a teacher of the rural school want to be eligible for the prize and win the contest. To do this, you must present (through the 5Q model, exposed in class) a teaching activity with the use of ICT to develop with the students of this rural school that allows you to place yourself at the head of the awards launched by the Ministry of Education.

You can choose the subject and theme you want to design your proposal, which must always be oriented to the integration of digital tools in the classroom in a didactic and innovative way.

Based on this assumption, the students of the Educational Informatics subject had to carry out an exhaustive analysis and study of it in order to design -, in groups of 4 people -, an innovative project in the educational use of digital tools for a school context very defined and close to reality. [14]

Once the teachers established the bases of the project, they had to translate them into a document, following defined guidelines in the classroom, which were called Model 5Q. This model consisted of several sections, from which the students presented the delimited project by answering 5 fundamental questions (Fig. 1):

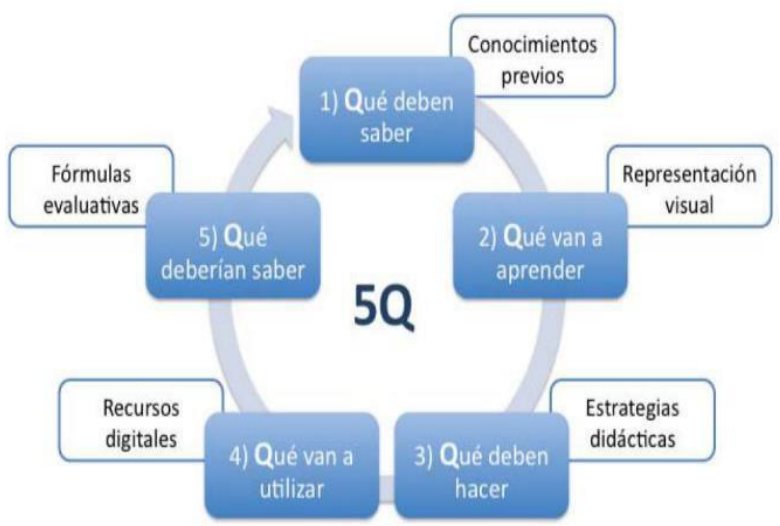

Fig. 1. Elements of the 5Q Model that students had to use to present their innovative projects in the use of digital tools.

1) What should they know?

It was necessary to determine the previous knowledge that the rural school students should possess in order to understand and acquire the new learning that would be presented to them, causing a scaffolding between the knowledge already acquired and the new ones.

2) What are they going to learn?

In the form of visual representation (mind maps, concept maps, diagrams, graphs, etc.) the students had to provide a summary with the most important ideas and topics to be addressed, in order to focus attention on the pertinent information and show the relationships that are established between the different parts of the content.

3) What should they do?

The students of the Educational Informatics subject had to define various didactic strategies that would guide and orient the proposal of activities as a means to promote new forms of teaching, aimed at developing more active and flexible methodologies (based on research, problem solving, in simulation, etc.) with the constructive use of digital tools.

4) What will they use?

In this section, students had to specify the technological resources necessary to carry out their innovative proposal in the use of digital tools. To do this, they had to present, in a contextualized way, the Web resources that they were going to use, in such a way that their capacity to support reflection, analysis, understanding, etc. as well as its educational potential.

5) What should they know?

Finally, the students had to establish how they would carry out the assessment of learning from an innovative approach. Therefore, it was necessary to choose those evaluative tools that best fit the new methodologies proposed in the projects. Among them, we highlight the use of evaluation rubrics.

\section{Competences to Develop}

All educational planning should be aimed at the comprehensive development of the student through the 
empowerment and acquisition of different skills, through the setting of tasks that involve the development of various strategies that promote learning. With the completion of the training activity, it is intended that students acquire and consolidate a set of skills and competences of a transversal nature aimed at promoting constructive training based on the promotion of innovative and creative ideas. Thus, with the design of the project, the teachers had to put into play:

1) Instrumental skills; referring to cognitive skills and methodological capacities to adapt to the environment, as well as technological and linguistic skills. In this case, the students put their skills and abilities into practice:

- Cognitive; to correctly apply the theoretical foundations necessary to plan and create an innovative project with the use of digital tools.

- Methodological; for problem solving and decision making necessary to carry out the project.

- Technological; for the efficient and effective use of new technologies, in this case, for a specific educational context.

- Linguistics; aimed at knowing and properly using written communication processes.

2) Interpersonal skills; referring to those skills necessary to develop a process of criticism and self-criticism, as well as the social skills used in the execution of collaborative work. In this way, the students put their communication and social skills and abilities into play to work as a team.

3) Systemic competences; in relation to the capacity of integrate understanding, sensitivity and knowledge that allow to give an overview of the global reality. Thus, teachers developed and / or consolidated their ability to apply theoretical content in practice; to generate innovative ideas and encourage creativity; for project design and management, etc.

\section{RESULTS}

At the end of the training activity, information was collected through a satisfaction survey carried out for this purpose, which included 5 items in which, through open questions, the students were satisfied with their global vision $(N=21)$ and the experience. Likewise, interesting information was obtained from the observations made throughout the event [15].

Therefore, it was found that more than $86 \%$ of the students found the proposed task attractive. According to $82.3 \%$ of teachers, they mainly use their ability to develop and coordinate collaborative projects. More than $79 \%$ of people said that executive activities are the first way to enter the world of work because they face a very special situation and must plan educational interventions based on the use of digital tools.

According to the opinions expressed by $75.5 \%$ of the students, the experience based on carrying out projects was very positive for them and they acknowledge that they perceived the need to carry out careful prior planning before incorporating new technologies in the classroom.

After the experience, it was found that the main difficulty encountered by about $57 \%$ of the students was that the task had to be done collaboratively. Although the groups were created by themselves, based on related interests and themes, some problems arose to coordinate and manage the different projects, which were solved throughout their development.

\section{CONCLUSIONS}

In a training action, various strategies can be proposed to develop different types of learning: problem solving, based on research, case studies, etc. With them, active, constructive and real learning can be promoted, while it is possible to provoke an innovative process.

From here, the students were asked to carry out a project of curricular integration of new technologies from a practical assumption that would guide their educational proposals. This meant a change in the conception of the teaching process, which was based on the practical application of the contents addressed in the subject and on the integration and didactic use of digital tools.

The experience carried out was valued very positively by the participating students, since, as they declared, it was a first approach to the professional field. Likewise, they showed great interest and motivation towards the proposed task, as could be observed throughout its development. And, it was verified how the teachers participated actively and perceiving the need to plan and project all training activities in the use of new technologies.

Likewise, the teachers stated that they develop and consolidate different skills and competencies among them, mainly those closely related to the planning and management of a project, followed by the social skills used in the execution of collaborative work.

In short, the proposed activity has used a methodology aimed, in this case, to promote the didactic integration of Web 2.0 and promote the collaborative work of students to acquire different skills aimed at stimulating their cognitive activity.

\section{CONFLICT OF INTEREST}

The authors declare no conflict of interest.

\section{AUTHOR CONTRIBUTIONS}

Juan Encinas and Mario Chauca conceived of the presented idea, all authors worked on the analysis and methodology of the research. All authors contributed and had approved the final version.

\section{REFERENCES}

[1] C. S. Christensen, M. Horn, and C. Johnson, Disrupting Class: How Disruptive Innovation Will Change the Way the World Learns, New York: McGraw-Hill, 2018.

[2] C. Christensen and H. Eyring, "The innovative university: Changing the DNA of Higher Education form the inside out," JosseyBass, 2018.

[3] M. Cebrian, "Virtual teaching for university innovation," Madrid: Editorial Narcea, 2017

[4] E. Danneels, "Disruptive technology reconsidered: A critique and research agenda," Journal of Product Innovation Management, vol. 21, no. 4, pp. 246-258, 2014.

[5] A. Hannan and H. Silver, "Innovating in higher education: Teaching, learning and institutional cultures," Buckingham: Open University Press, 2015. 
[6] G. Grosseck, "To use or not use Web 2.0 in higher education?" Procedia-Social and Behavioral Sciences, vol. 1, no. 1, pp. 478-482, 2017.

[7] R. Barnett, The Ecological University: A Feasible Utopia, Routledge, New York, 2017.

[8] J. Dewar, "University 4.0: Redefining the role of universities in the modern era," Higher Education Review, 2017.

[9] A. Pulido, "The university on the other side of the mirror," Blog about Future and Innovation, 2019.

[10] J. Laviña and L. Mengual, White Paper of the Digital University 2010, Barcelona, Ariel, 2008.

[11] L. Nadelson, "Discourse: Integrating problem solving and project-based learning in high school mathematics," Northwest Teacher, vol. 1, no. 1, pp. 20-31, 2016.

[12] M. Mangelsdorf, "These are good times for disruptive innovation," Harvard Deusto Business Review, vol. 181, pp. 4-9, 2016.

[13] J. Salinas, A. Pérez, and B. Benito, "Student-centered methodologies for online learning," Madrid: Editorial Síntesis, 2014.

[14] A. Sutinen, "Constructivism and education: education as an interpretive transformational process," Studies in Philosophy and Education, vol. 27, no. 1, pp. 1-14, 2012.

[15] R. Walker, "Conducting case studies in education. Ethics, theory and procedures," New Reflections on Educational Research, Madrid: Ed. Narcea, 2010.

Copyright $\odot 2021$ by the authors. This is an open access article distributed under the Creative Commons Attribution License which permits unrestricted use, distribution, and reproduction in any medium, provided the original work is properly cited (CC BY 4.0).

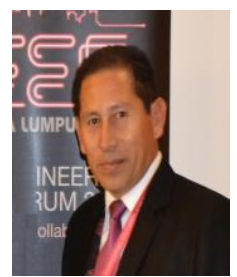

Mario Chauca is a doctor, RENACYT-CONCYTEC Database Peruvian researcher, reviewer of events indexing in Web of Science, Scopus, IEEE xplore, IEEE International Midwest Symposium on Circuits and Systems (MWSCAS), Steering Committee, Ex-fellow NIPA - KOREA and AOTS - JAPAN in information technology and technologies respectively, past director and member of AOTS-Peru, IEEE Peru and of papers published in Scopus, WoS, IEEExplore and others.

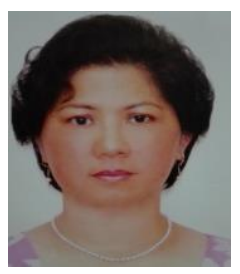

Ynes Phun is doctor of education; magister in education, planning and administration of higher education; second specialty in psych pedagogy; in educational projects and culture of peace. Teacher attached to the Faculty of Biological Sciences of the National University San Luis Gonzaga. Research related to the fauna of invertebrates in the Laguna de Huacachina, Ica and the Ica Region, Peru. Specialist teacher in the National Training Program for in-service teachers (PRONAFCAP); Research related to learning strategies; Beginning in qualitative research of the research-action type, with the support of ICTs. She studies in neuroeducation.

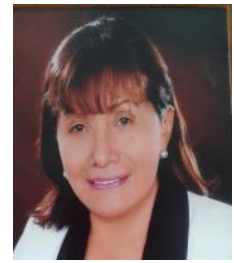

Olga Curro was got the degree in nursing from the Universidad Femenina del Sagrado Corazón, the master's degree in administration and planning of higher education, doctorate in Public Health (UNFV). Specialty in emergencies and disasters. Professor at the San Luis Gonzaga National University in the Faculty of Nursing, of the Department of Community Family Health and Research. She is one member of the internal Licensing and accreditation committees of the Faculty of Nursing, evaluator of labor competence (Mexico 2022. Active member in ReDdolac, Network of Teachers of Latin America and the Caribbean.

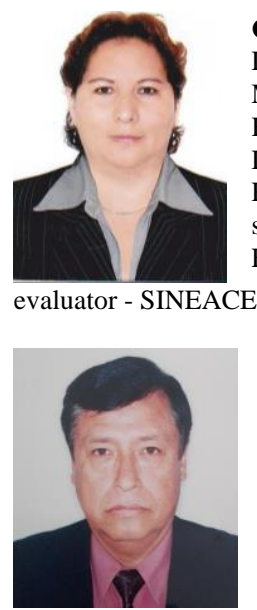

Carmen Chauca got the bachelor of Dentistry-UNICA Title of Dental Surgeon-UNICA Magister in Dentistry-UNICA Doctor of Public Health-UNICA Postgraduate degree in Pediatric Dentistry-UBA-ARGENTINA Specialty in Oral Radiology and Maxillofacial- UNICA Diploma of study in Senior Management in University Higher Education CENTRUM CATOLICA. external

Ramiro Yallico is a doctor in education, $\mathrm{Mg}$. in dentistry. Principal Professor of Exclusive Dedication at the Faculty of Education Sciences and Humanities.

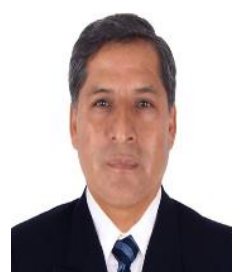

Virgilio Quispe is a dental surgeon, graduated from the San Luis Gonzaga National University of Ica, with a master's degree in dentistry and studies completed in education doctorates. With a specialty in oral rehabilitation with experience as an external evaluator of health programs of a higher technological level Currently he works as a teacher of technological higher education and private practice as a specialist in oral 